\title{
Efficacy of correction beliefs related to family functioning based on cognitive method to reduce marital conflict in men
}

\author{
Mohammad Hojati ${ }^{1,}$, Mohammad Abasi ${ }^{2}$, moein shokri ${ }^{3}$ \\ ${ }^{1}$ Young Researchers Club, Kermanshah Branch, Islamic Azad University, Kermanshah, Iran \\ ${ }^{2}$ Department of Education, shadegan Branch, Islamic Azad University, Shadegan, hkozestan, Iran \\ ${ }^{3}$ Islamic Azad university- harsin branch
}

\section{Email address:}

Naser.h63@gmail.com (M. Hojati)

\section{To cite this article:}

Mohammad Hojati, Mohammad Abasi, moein shokri. Efficacy of Correction Beliefs Related to Family Functioning Based on Cognitive Method to Reduce Marital Conflict in Men. American Journal of Applied Psychology. Vol. 3, No. 1, 2013, pp. 8-11.

doi: 10.11648/j.ajap.20140301.12

\begin{abstract}
This study examines the effectiveness of the correct relationship beliefs about family functioning, based on Cognitive method to Reduce Male Marital Conflict. The research method used in this study is quasi-experimental. Research design is pre-test and post-test design with a control group. The study population consists of all married men who referred to a clinic in an oil company in jam, Iran. Among these patients, typical methods are used to fit 30 people that sampling method was selected and, 15 people were randomly placed in the experimental group and 15 people were in the control group. The experimental group participated in eight 60-minute sessions. The tools used in this study were Contact Beliefs Questionnaire (RBI) and the Inventory of marital conflicts. Before and after implementation of the independent variable (Correct relationship beliefs) members of both groups were asked to respond to the questionnaire. Data analysis for this study was spss16 software. In order for describing the data, descriptive statistics (such as mean and standard deviation of frequency), and $\mathrm{T}$ tests were used to test the research hypothesis. The results showed that the Correct Relationship beliefs related to family functions based on the cognitive method in reducing marital conflicts that affect men.
\end{abstract}

Keywords: Relationship Beliefs, Family Functioning, Marital Conflict, Cognitive Therapy

\section{Introduction}

Marriage is one of the most important events in human life that not only affects one's physical and mental health, but also has an important role in public health. Marital conflicts are difficult for many reasons. Conflict is inevitable in human relationships with each other. Conflict is a common phenomenon in human relationships. However, the marriage must therefore be assumed that the conflict is part of the marital relationship and marital life is with everybody, for feeling prosperous the couples must learn to resolve their conflicts. If not, the action may take them apart, or when the conflict grows up and enters their house and eventually suspended and remains latent in the couple's divorce after years of marital life (Sana'i Zaker, 1996, quoted Mousavi et al, 2005).

On the other hand, an intimate marital relationship requires learning of couples to communicate with each other if that are different (Young \& longe1988, quoted Afkhami et al, 2007).

Ameri (2002) stated that the result of a research in contemporary Iranian relationship has been subject to structural changes and there changes in the distribution are observed too. This in turn can cause problems in the family system and even push it to the list. The foundations of interpersonal communication, perfection of human identity are the basics for relationship with others. Prosperity and improve the quality of relationships is effective communication. In addition, effective communication prevents human flourishing and destroys relationships (Sohrabi, 2003). According to Johnson (2002) Interpersonal influence has a direct effect on mental health, personal growth and identity of individuals help increase productivity and business success, improve quality of life, increase the compatibility that can decrease the stress and causes to feel prosperity (Fata et al, 2006).

In short, troubled couples the negative things their spouse 
are believed to be deliberate and reprehensible behaviors of their wife. This is the best place to study the documents and the effects of these issues be addressed to increase appropriate behavior and communication, and ultimately leads to increased satisfaction among couples (Siqueland, Rynn, \& Diamond, 2005; Halfvrd, 2003). Several studies have been conducted on the effects of incompatible believes about intimate relationships have been identified. Most work in this area has been based on the ideas of Albert Ellis. Ellis believes that marital conflict can be justified by irrational couples. Although the causes of explanation has offered a different view of communication problems but this position has a prominent place in the cognitive approach (Mazaheri, 2002). According to this view, emotions and behaviors, inappropriate behavior of turbulent disabled spouse or life problems and not the problems but much of it could be due to believes and attitudes about the behavior of one or both of them or have difficulties in life (Nickel, 2006).

In addition, Ellis (1984) believes that conflicts and disagreements are due to two factors: 1- Relationship believes 2- Significant discrepancies. The Ellis family grievances and conflicts due to their excessive reliance on one or more believe that are unrealistic and utopian state. Couples Believes are often full of expectations (Farahbakhsh, 2005). So what was said investigators have sought to answer this question that correct believes based on communication methodology can reduce marital conflict?

\section{Methodology}

The research method is quasi-experimental research. Quasi-experimental research design that will be used in this research is Pre-test and post-test design with a control group. The design is shown below:

Table 1. Quasi-experimental research model

\begin{tabular}{lcccc}
\hline & pretest & $\begin{array}{l}\text { Independent } \\
\text { variable }\end{array}$ & posttest & $\begin{array}{c}\text { Random } \\
\text { selection }\end{array}$ \\
\hline $\begin{array}{l}\text { Experimental } \\
\text { group }\end{array}$ & $\mathrm{T} 2$ & $\mathrm{X}$ & $\mathrm{T} 1$ & $\mathrm{RG} 1$ \\
Control group & $\mathrm{T} 2$ & - & $\mathrm{T} 1$ & $\mathrm{RG} 2$ \\
\hline
\end{tabular}

\subsection{Statistical Society}

The population is married men admitted to the clinic in the Town of Unity Oil Company the jam. The sample used is 30 that the sampling methods selected and of these 15 were randomly assigned to an experimental group and a control group of 15 people were selected. The experimental group participated in eight 60-minute sessions. Before and after implementation of the independent variable (Correct relationship beliefs) of the members of both groups were asked Relationship Believes Inventory (RBI), and to answer the question of marital conflict. The all participants had been married two years.

\subsection{Data Collection Tools}

Relationship Believes Inventory (RBI)

This questionnaire is 40 questions. An irrational believes about marriage which is measured by Epstein \& Eidelson (1981) is made and Has 5 subscales that include:

1. Believe that the Disagreement is destructive means rejection, discomfort and disagreement is interpreted as negative.

2. Believed to be the Partner cannot change. Convinced of his wife's ability to change behavior and repeat them in the future.

3. Mind reading is expected. No need to say, and said it expected to, the person's feelings, thoughts, and needs to know his wife.

4. Sexual perfectionism. Expect a full partner in a sexual relationship he is in all circumstances, regardless of the circumstances.

5. Believed to be the sexes are different. Lack of understanding of the cognitive and physiological differences between men and women as having the same expectations and knowing the difference is due to the congenital differences.

Epstein \& Eidelson (1982) in their study showed that Cronbach's alpha reliability coefficient for the sub-scales of 72 to 81 percent estimated And also by emel Kamp R, Kroll, Sanderman and Rafan (1987) for internal reliability (Montains 74, 83) and test-retest reliability was $r=76 \%$ (Mazaheri, 2002). The Persian version of this tool translated by Mazaheri and Poor etemad (2001) and revised by re-taken method. Cronbach's alpha was calculated at $75 \%$ or more. This questionnaire is a Likert-type answer and participants are expressing their opinion about each statement in one of the options: (0) is completely wrong, (1) is false, (2) is wrong or is likely to make more mistakes, (3) is correct or more likely true to false, (4) is true, And (5) are quite true. High scores indicate relationship believes are irrational.

\subsection{Inventory of Marital Conflict}

"Inventory of Marital Conflict" is a 42 questions to assess conflict couples and Based on clinical experience is made By "Sanaei and Barati" and statistical methods under the guidance of "Pasha Sharifi". Grading: For each of the five options considered the proportion of 1 to 5 points assigned to them. The maximum total score is 210 and the minimum 42 . This means higher scores indicating greater conflict and lower score means better relationships and less conflict. Cronbach's alpha Obtained for the entire questionnaire in a group of 32 people, 53/0. Also marital conflict has good content validity of the questionnaire. 47 questions about the reliability coefficients form a group of 11 patients was calculated using alpha coefficient That reliability coefficient Obtained of 95/0 (Soleimanian, 1994).

\subsection{Sessions Summary}

First Session- More familiar with each other and members 
of the advisory group, tell something about the couple's relationship, Family and its impact on community health, General speech applications. The second Session- An overview of the material presented in the previous Session, Types of belief and relationship believes, Scientists theory in the field, Understanding their believes and identifying factors trigger it. The third Session- Following tasks in the previous Session, Detailed explanation of the irrational relationship believes. The Fourth Session- Define and explain that the expectation of mind reading, Identification and selection of alternative rational beliefs. The Fifth Session- Mental imagery training to clients in order to increase their ability to control emotions and irrational beliefs are correct. The Sixth Session- Explained that the sexual perfectionism, the Identification of rational Discuss-self impact. The Seventh Session- Teaching the correct way to communicate. The Eighth Session- Review Previous Session and implementation post test.

\section{Results}

The present study is performed In order to Evaluate the effectiveness of the correct relationship believes related to family functions Based on Cognitive Methods for marital conflicts Decline in married men, Descriptive analysis of the data showed that Age group of 31 participants in the experimental group and the control group, mean age was 30 years. The age range of participants was between 26 to 37 . As well as Mean of beliefs relationship of the experimental group in pre-test was $1 / 144$ and the post test $1 / 109$ But the pre-test control group $1 / 134$ and the post test $1 / 136$. Also Average variable marital conflicts in pre-test and post test for experimental Group Was 1/296 and 1/358 Respectively In the pre-test and post test for Control Group Was 1/348 and 1/355 Respectively. While the standard deviation of the variable relationship beliefs Experimental group was at pretest $9 / 854$ in post test $8 / 413$. But the pre-test control group was $9 / 417$ and in post test $9 / 147$. Also, the standard deviation of the variable of marital conflict in the pre-test and post-test for Experimental group was 19/916 and 16/860 and the pre-test and post test for control group was 19/194 and 19/766 respectively. Although analytical data through the use of the T test about the two research hypotheses is shown below.

First hypothesis: Correction efficacy believes related to family functioning Based on a cognitive method in Reduce conflicts married men marriage.

Table 2. Comparison differences between of marital conflict of post test mean control and experimental groups.

\begin{tabular}{llllll}
\hline & $\begin{array}{l}\text { Mean } \\
\text { deference }\end{array}$ & $\begin{array}{l}\text { Std. } \\
\text { deviation }\end{array}$ & t & $\begin{array}{l}\text { Degre of } \\
\text { Freedom }\end{array}$ & sig \\
\hline $\mathrm{T}$ test & $5 / 600$ & $1 / 144$ & $3 / 855$ & 28 & $0 / 001$ \\
\hline
\end{tabular}

According to the above mentioned table the results of $t$ test show with $95 \%$ Confidence, Teaching of Correct the relationship believes related to family functions Based on cognitive method affects in reducing marital conflict among men. And the differences observed between the two groups are not due to chance factors and Main hypothesis was confirmed.

Second hypothesis: Effectiveness Survey of cognitive method correct relationship believes related to family functioning Married Men.

Table 3. Comparison differences of relationship beliefs mean between Experimental and control group in post test.

\begin{tabular}{llllll}
\hline Index & $\begin{array}{l}\text { Mean } \\
\text { deference }\end{array}$ & $\begin{array}{l}\text { Std. } \\
\text { deviation }\end{array}$ & $\mathbf{t}$ & $\begin{array}{l}\text { Degree of } \\
\text { Freedom }\end{array}$ & sig \\
\hline T test & $3 / 600$ & $1 / 094$ & $3 / 290$ & 28 & $0 / 003$ \\
\hline
\end{tabular}

According to the above table the results of $t$ test show with 95\% Confidence, Teaching of Correct the relationship beliefs related to family functioning Based on a cognitive method Is effective in the correct communication beliefs about family dysfunction in men. And the differences observed between the two groups isn't due to chance factors and Main hypothesis was confirmed.

\section{Conclusions}

The aim of this study was to evaluate the effectiveness of the correct relationship believes related to family functions, marital conflicts Based on a cognitive method to be reduced among men. And two hypotheses were proposed that the hypothesis of the study and the results are discussed below:

First hypothesis: Correction efficacy believes related to family functions Based on a cognitive method to Reduce conflicts married men. The $t$ test results in Table 1 show that with 95\% Confidence Teaching with correct beliefs about family functions, based on a cognitive method is effective in reducing marital conflict in men.

Second hypothesis: Effectiveness Survey of cognitive method the correct relationship believes related to family functioning Married Men. The t test results in Table 2 show that with $95 \%$ Confidence Teaching with correct beliefs about family functioning, based on a cognitive method Is effective in correct beliefs about family functioning in men. This hypothesis is consistent with the result of the following investigation.

The results show that emotion, emotional development and adjustment of among the couples are related (Lin, \& Detels, 2011; Pyasntyny et al, 2011).

Michel (1971) in Their studies on 450 pairs Says that Women are more satisfied of Their life which Involved in planning, funding, equipment and housing, children's education and children whose husbands. His results showed that Satisfaction with interchangeable roles of husband and wife is related to decision making (Quoting Azad \& naseebolboka, 2001).

Research has shown Kind of leadership (Family involvement and choice in decision making) not without effect on life satisfaction than couples (Myers; 1993) and if a couple insists on imposing its power and authority, 
somewhat Pose a risk to the family (Landis; 1996, Quote from Saeidian et al, 2008).

Hill and Peplan (1998) in their longitudinal study The 231 couples interested in comparing pairs separated by two years concluded that The most important factor in survival between successful couples are similar in many ways, such as planning, age, intelligence and physical attractiveness And unsuccessful couples Have mentioned as a reason for their separation Differences in interests, tastes, thoughts, beliefs, sex expectations, lack of experience or lack of equal marriage equality in intelligence (Quoting Banny Jamali et al, 2004).

Finally we can say Marriage is based on the formation and development of the relationship between two individuals and this relationship strongly is influenced by the thoughts and believes of the couples. Familiar with these ideas, knowledge and proper ways of communication has a crucial role in marital satisfaction. In addition, According to the several studies on the effectiveness of treatment programs have shown to reduce marital conflict, In this regard, encourage health professionals and couples counseling the choice of testing methods And new approaches to treatment and update Counseling and couples therapy in our community And evaluate the efficiency, Compliance with the terms and conditions of the families and couples Seems to be essential. This study was also an important step towards achieving this.

\section{References}

[1] Azad, Hussain. (2001). Comparison of characteristics and personality in compatible and incompatible pairs in Tehran. Khorasgan Islamic Azad University, Science and Research (Esfahan). Education and Psychology. Nos. 11 and 12, pp. 117 to 134 .

[2] Afkhami, Aymanh. Bahrami, Fatemeh Et al (2008). Investigate the association between marital conflict and relief in Yazd. Paper presented at the Third National Congress of Family Pathology: Shahid Beheshti University.

[3] Ameri, F. (2002). Effect of strategic family therapy interventions in marital disputes. $\mathrm{PhD}$ thesis. Tarbiat Modares University.

[4] Bernstein, Philip and Bernstein, Marse, tee. (2003) Cognitive therapy and marital disputes. Translated by Hamid Reza Sohrabi. Tehran: rasa Cultural Services.

[5] Ellis, A, Diguiseppe, R, DiMattia, D.J., Sichel, J.L, \& Yeager, R.J. (1989). Rational- emotive couples therapy .New York: Pergamon press.

[6] Ellis, A. (1962). Reason and emotion in psychotherapy. New York: Lyle Stuart.

[7] Epstein \& Eidelstei. N, (1982). Cognitive and relationship maladjustment: Development of a measure of dysfunctional relationship beliefs. Journal of Consulting and Clinical Psychology, 50,715-720.
[8] Ellis, A, Diguiseppe, R, DiMattia, D.J., Sichel, J.L, \& Yeager, R.J. (1989). Rational- emotive couples therapy .New York: Pergamon press.

[9] Ellis, A. (1962). Reason and emotion in psychotherapy. New York: Lyle Stuart.

[10] Epstein \& Eidelstei. N, (1982). Cognitive and relationship maladjustment: Development of a measure of dysfunctional relationship beliefs. Journal of Consulting and Clinical Psychology, 50,715-720.

[11] Fata, L.; Mvtaby, fereshteh; Mohammad Khani, S. and kazem zadeh, M. (2006). Life skills training. Tehran: Publication Danzhh.

[12] Farahbakhsh, K. (2004). Comparison of the efficacy of couple therapy techniques Ellis's theory, combining them Glasrv reducing marital conflict. PhD thesis, University of Allameh Tabatabai.

[13] Halfvrd, Kim. (2005). Short-term couple therapy, translated by Mustafa Tabrizi, foroogh Jafari, mozhdeh kardan. Tehran: Publications face.

[14] Lin, Z. Detels, R. (2011). Family support, quality of life and concurrent substance use among methadone maintenance therapy clients in China. Public Health, Volume 125, Issue 5, Pages 269-274.

[15] Mazaheri, Mohammad Ali, Heidari, Mahmoud (2002). A preliminary study on the role of cognitive skills marital relationship beliefs in changing students' psychological journal, year VI, No. IV.

[16] Mousavi, Ashraf Sadat (2003). Functional family therapy with a systems approach, Institute for Women's Press.

[17] Nickl, K. 1. (2006). The Relationship between Irrational Beliefs and Marital Satisfaction, Submitted in partial fulfillment of the Requirements for the Degree of Doctor of Philosophy in Educational Psychology Northern Arizona University.

[18] Piacentini, R. Bergman, L, Chang, S. Langley, A, Peris, T, Jeffrey J. Wood, McCracken, J. (2011). Controlled Comparison of Family Cognitive Behavioral Therapy and Psychoeducation/Relaxation Training for Child Obsessive-Compulsive Disorder. Journal of the American Academy of Child \& Adolescent Psychiatry, Volume 50, Issue 11, Pages 1149-1161.

[19] Saeidian, f., (2003). The Investigation of relationship between the power structure of the family conflicts, marital counseling, Master Thesis, Tarbiat Moallem University of Tehran.

[20] Sanaei, B. et al. (2008). Measures of family and marriage. Besat publications.

[21] Siqueland, L, Rynn, M, Diamond, (2005). Cognitive behavioral and attachment based family therapy for anxious adolescents: Phase I and II studies. Journal of Anxiety Disorders, Volume 19, Issue 4, Pages 361-381.

[22] Soleimanian, A. (1994). Of irrational thoughts based on a cognitive approach to marital dissatisfaction. MSc Thesis, University of Teacher Education. 